\title{
ESTRATÉGIAS DE ESCRITA TEATRAL NÃO-DRAMÁTICAS E A OFICINA DE DRAMATURGIA NO CONTEXTO CONTEMPORÂNEO: ALGUMAS REFLEXÕES PRELIMINARES
}

\author{
Prof. Dr. Stephan Baumgärtel \\ PPGT/UDESC ${ }^{1}$ \\ stephao08@yahoo.com.br
}

A maioria dos manuais sobre dramaturgia teatral acessíveis não só no mercado brasileiro, mas também de língua inglesa e alemã estabelece uma relação estreita entre trama e personagem; ainda concebe a ação teatral enquanto linear e causal e foca numa linguagem mimética predominantemente figurativa. Essas ênfases, entre outros, revelam uma fidelidade desses manuais ao drama rigoroso enquanto modelo de escrita teatral. Entretanto, as práticas de escrita realizadas por autores europeus a partir dos anos $60 \mathrm{e}$ 70, como, por exemplo, Peter Handke, Michel Vinaver, e posteriormente Heiner Müller e Bernard-Marie Koltés nos anos 80, já não condizem com os princípios formais dessa dramaturgia. Esses autores difundiram uma escrita teatral que solapa os fundamentos do drama e coloca em questão os princípios da mimese realista. A crise dessa mimese se tornou visível também no Brasil ainda durante a ditadura militar e antes da queda do muro de Berlin, evidenciando que na base dela está não só o fím das grandes narrativas de libertação, mas também o modo como as novas tecnologias são introduzidas pelo capital nas sociedades contemporâneas.

\section{A crise do drama enquanto crise do logos realista no contexto brasileiro}

Nesse contexto particular, Mariângela Alves de Lima constatou em um artigo de 1981 que a sociedade brasileira se tinha tornada complexa e contraditória demais para poder ser descrita adequadamente por uma dramaturgia analógica, ou seja, a partir de procedimentos realistas. A intervenção necessária a ser realizada sobre a imagem 
realista podia nascer da aceitação de uma simultaneidade de mundos conflitantes no imaginário do artista. Diz ela:

O fato é que não há mais um monstro fora da sala de estar das famílias pequenoburguesas. A sala é claramente um conjunto hipotético e o monstro está cravado no cotidiano sem que se possa combatê-lo com uma estratégia coerente. Uma simples operação analógica não basta para ligar o sujeito à coletividade. Consequentemente a produção artística, dentro desse mundo de fronteiras móveis, alterou-se consideravelmente. Cada etapa do trabalho é uma investigação de identidade e de pontos de partida, sem que o processo se complete numa única obra. Seria ilusório querer preservar a produção do texto dramático do 'contágio' dessa instabilidade. O mais provável é que a boa dramaturgia venha a se tornar tão ambígua, múltipla e sugestiva a ponto de acolher a confusão agônica de todos os artistas que a utilizam como um dos seus materiais de trabalho. (AlVES DE LIMA, 1981, p.11)

Mas se o realismo burguês, com seu enfoque na possibilidade de reconhecer o mundo ficcional como imitação do mundo empírico do espectador, não é mais capaz de expressar as forças reais da formação desse último, ele tampouco consegue mais realizar "formar um público", simplesmente por não ser mais capaz de tocar os nervos e o âmago emocional dos espectadores.

De fato, a crise do drama enquanto forma teatral fez com que alguns dramaturgos brasileiros começaram a experimentar com formatos pré-dramáticos (o Auto, a missa, o mistério) ${ }^{2}$ ou não-dramáticos (a peça monológica, a peça simbolista, a peça paisagem $)^{3}$ introduzindo no formato do drama elementos alheios à estética representacional realista do drama, como por exemplo, o fantástico e o surreal com suas transformações dos eixos temporais e locais da ação, e mais importante ainda, utilizando uma linguagem poetizada ou até jogos de linguagem. ${ }^{4}$ Estamos perante uma busca dramatúrgica que tenta substituir a lógica do realismo burguês não só por uma lógica não-realista, mas por uma escrita com uma multiplicidade de centros. Ela trabalha com a forma do drama, inserindo nela outras percepções epistemológicas, e portanto, outras lógicas cênicas. No meu ver, essa multiplicidade de vetores temáticos e estruturalistas, 
junto com a relativa autonomia das linguagens cênicas, faz com que a lógica dos textos teatrais deve ser compreendida como uma estética de produção.

\section{Uma escrita contemporânea além do logocentrismo}

A crise do drama pode ser lida também como uma crise da arquitetura dramática e de seu alicerce na ideia do logos enquanto força hierárquica e causal (LEHMANN, 1997, p.56). O motivo para que esse aspecto chegou à consciência dos artistas é em parte histórico, mas também estrutural. Logos aqui não significa simplesmente um enfoque na palavra, mas o enfoque em uma forma fechada que concatena as ações de tal modo a garantir a eficácia da ação. É o logos enquanto força formadora que garante a identidade entre as ações apresentadas e o tema representado, ou seja, a força presencial do espetáculo. Nesse sentido, na busca por um teatro não-dramático e por um texto além desse logos, "[w]hat took place was [...] the complicated and meandering development of new visions of multiple logos and a new kind of architecture. [...] [a] searching for and constructing spaces and discourses liberated as far as possible from the restraints of goals (telos), hierarchy and causal logic" (LEHMANN, 1997, p.56).

A transformação que Alves de Lima e Lehmann têm em mente solapa tanto a estrutura fixada e centrada da linguagem humana enquanto sistema, ou seja, o sujeito logocêntrico, quanto a fábula enquanto organização desse logos por meio de uma histórica com início, meio e fim (ou tese-antitese-sintese nos moldes hegelianos). Segundo Elinor Fuchs (1985), foi o trabalho de Jaques Derrida que ajudou a derrubar o logocentrismo também na prática teatral e estabelecer a noção de textualidade enquanto característica principal da realidade cênica. A eficácia cênica depende mais da instalação de um constante deferimento de plenitude no jogo semiótico, do que da presença de uma plenitude nesse jogo.

De fato, a textualidade de Derrida é sempre uma intertextualidade descoberta no interior da escrita por meio de uma leitura minuciosa das inconsistências no interior de um texto. "Trace-structure, everything always inhabited by the trace of something that is not itself, questions presence-structure." ${ }^{\text {" }}$ A existência desses traços não implica em arbitrariedade ou em um caráter onírico do texto. Não se trata de substituir o centro 
racional por um centro inconsciente ou libidinal, até por que esse não possui centro, mas se expressa por uma incessante dinâmica de signos que remete a diferentes forças transindividuais (sociais, libidinais, espirituais), as quais a consciência racional-afetivacorporal do ser humana apenas organiza. Portanto, a escrita além do logocentrismo visa dispersar tradicional centro racional cartesiano desdobrando-o em vários focos e vetores de significação, deslocar o sujeito enquanto agente unificador para transformá-lo em um portador de múltiplas vozes para, desse modo, instalar um jogo dinâmico que desestabiliza a produção de um sentido único para essa textualidade.

Ora, me parece importante entender que essa inter- e intratextualidade, a presença num texto teatral de traços de uma voz do outro, de outro(s) texto(s), não é um mero jogo formalista, mas que esse formalismo abre o texto e o(s) sujeito(s) inscrito(s) nele para o mundo da história e do social; que o surgimento de traços do outro não pode evitar a tematização de uma relação de poder entre traço marginalizado e centro dominante, bem como a relação entre as distintas vozes e as condições de seu (des-) aparecimento e sua (in-) audibilidade.

Essa escrita possui seus autores também dentro de uma estética textual predominantemente representacional. ${ }^{7} \mathrm{O}$ que a torna contemporânea é a inclusão da performatividade linguística enquanto dimensão de uma linguagem verbal nãofigurativa e o direcionamento do texto para o eixo palco-theatron. Não se trata do texto como representação de uma intriga, mas do texto enquanto palco do verbo, da palavra em ação, cujo principal endereçado não é um personagem ficcional, mesmo quanto estamos perante de uma estrutura formalmente dialógica, mas o espectador. O texto teatral assume características de um poema dramático ou de um epos lírico, sem necessariamente perder por completo seus traços dramáticos. O que acontece é uma inversão de hierarquia, do eixo intra-ficcional com sua estética representacional para o eixo palco-plateia alicerçado numa estética performativa.

\section{Algumas ferramentas dramatúrgicas para o texto não-dramático além do logocentrismo}


Nessa abertura do formato do drama para elementos não-dramáticos, a manipulação dos dois eixos de comunicação teatrais e a transformação de uma estética representacional para uma estética de produção se sobrepõem à construção de uma intriga no que diz respeito às principais ferramentas do dramaturgo de construir o eixo temático de seu texto teatral. Ambas as mudanças apontam para um deslocamento claro do centro de significação, da representação de uma ação ficcional significante para a exposição da ação de apresentar o seja, a ação teatral. Como argumentei em outro lugar, ${ }^{8}$ o agon se desloca da intriga ficcional para o conjunto dos signos teatrais, organizados no cruzamento dos dois eixos de comunicação. Embora essas transformações comecem a serem difundidas, quase não existem reflexões publicadas acerca dos impactos dessa mudança sobre as oficinas de criação de textos teatrais. Pretendo aqui pouco mais do que iniciar essa discussão.

Ao comentar brevemente sobre possíveis procedimentos de criação textual a partir dos traços formais da dramaturgia contemporânea, pretendo levar em consideração que uma boa parte dos processos criativos hoje em dia acontecem no contexto do chamado processo colaborativo. Portanto, a parte teórica dessa apresentação deve ser lida também como indagação não só dos processos estéticos da escrita contemporânea, mas também das percepções e habilidades que o ator contemporâneo necessita quando busca participar de um processo colaborativo de escrita contemporânea.

Sem querer estabelecer uma hierarquia, vou enumerar alguns traços formais da dramaturgia contemporânea. O primeiro aspecto dessa nova dramaturgia é a importância do aqui e agora da fala teatral, o que dramaturgicamente implica uma estrutura textual que evidencie principalmente seus procedimentos de criação e não focalize um universo ficcional, seja esse realista ou onírico-fantástico. ${ }^{9}$ Entretanto, a partir do momento em que se trabalha com palavras e frases, e não unicamente com sílabas e sonoridades, não há como evitar a dimensão referencial e ficcional num texto teatral. Isso implica para a oficina de criação de textos trabalhar com estímulos que sensibilizam o participante para a co-presença da dimensão ficcional ou representacional e da dimensão material ou performativa da palavra falada. É importante ajudar ao ator-criador a colocar-se na posição de um performer aqui e agora, 
e não no lugar de um representante de um mundo que existe "em outro tempo e lugar". Não se trata da tentativa de "imitar" um mundo empírico, mas de criar um universo verbal, cujo funcionamento interno permite referências ao mundo empírico.

Um segundo traço é o princípio da inter ou intratextualidade, ou seja, o trabalho com núcleos formais ou temáticos que aparecem em contextos distintos, de modo a provocar por meio desse deslocamento percepções acerca de seu surgimento e regulamento enquanto elementos ideológicos ou poéticos. Esses núcleos podem ser palavras isoladas, metáforas ou frases, ou estruturas sintáticas e morfológicas que aparecem estrategicamente colocadas no texto. ${ }^{10}$ Devido ao deslocamento, é possível fazer com que sejam percebidos como citações desviantes, como simulacros de uma situação de enunciação problemática. Exercícios para familiarizar-se com essa técnica podem incluir a criação de conjuntos temáticos de palavras que sejam inseridos em uma situação diferente da de origem. Trata-se de tentativas de evidenciar na fala de um ser ficcional não seu caráter, mas sua relação com um discurso que é uma força formadora não só das ações do ser ficcional, mas do universo temático do texto. Formalmente,

[d]iscourse, unlike dramatic or normal conversational language, is distinguished by coded words, 'buzz-phrases', often with a reliance on technical terms or argot. Underlining the strategy of a discourse is an essential ideology and historicity. To this extent, discourse is time bound. [...] Discourse gives character an ideological front or façade that may be activated strategically to empower, intimidate, moralize, or to aid and inform. In new playwriting, however, discourse tends to be more ruminative than argumentative, more marginalized than mainstream. It moves along by association and incremental repetitions rather thain by progressive trails of logic. In this sense, it is more dialogic, than dialectic. [...] Its dialogic and ruminative bent tends to personalize the rendering of language. ${ }^{11}$ (Castagno, 2001:26)

Um terceiro traço, em parte subproduto da intratextualidade e do foco na qualidade discursiva da linguagem, é o trabalho com a língua enquanto uma realidade polivocal, as experimentações com essa polivocalidade na linguagem de uma única figura teatral ou nos modos de um texto inteiro articular suas falas, e termos de registros, sociolectos ou dialetos. O que me parece importante nessa dimensão é a construção de uma tensão entre as características formais das falas e suas dimensões sócio-culturais e ideológicas. Para evitar um formalismo vazio, será necessário fazer a 
materialidade da fala com seus ecos culturais ressoar numa situação teatral que entrelaça as subjetividades dos seres ficcionais, dos atores e do público dentro de uma moldura coletiva, seja essa evocada predominantemente por meio de motivos temáticos, seja por pistas de uma intriga exemplar. Em parte, esse traço remete à construção de personagens-tipos, com a diferença que agora não se pretende criar uma coerência social, ou seja, não surge uma figura ficcional determinada em sua psicologia por seu status social. Antes, cria-se uma materialidade para a fala que expõe essa figura como um ser múltiplo e cindido, a partir de uma série de pontos de vista (sociais, libidinais, afetivos, etc.) que misturam as dimensões representacionais e performativas de tal modo que torna-se impossível uma descrição ou percepção objetiva dessa figura. Nesse contexto, é fundamental estimular os participantes de uma oficina a brincar com os traços representacionais (aqueles que aludem a uma realidade social, psicológica, familiar, etc.) de tal modo a enfatizar as possibilidades performativas desse material linguístico, as características formais e sonoras, para, num segundo passo, colocar essa materialidade e esse formalismo contra as dimensões representacionais.

Outro traço importante da dramaturgia contemporânea é uma abordagem nãopsicológica da figura teatral que se dissolve em estratégias linguísticas textuais ou em um conglomerado tático de estados figurativos que não compõem um personagem. ${ }^{12}$ Mas eles produzem e evidenciam a teatralidade e performatividade da situação teatral e/ou da linguagem verbal, e desse modo, indiretamente, a teatralidade da figura que é portador da enunciação. No que diz respeito à figura humana em cena, não se trata simplesmente de usar a linguagem para criar uma máscara verbal polifônica para um "personagem", mas de um projeto de investigar a relação mutualmente condicionadora entre linguagem/discurso e subjetividade. Além disso, quando encontramos no texto objetos ou animais enquanto figuras teatrais falantes, percebemos uma pesquisa sobre a capacidade da língua de criar universos possíveis e relacionar o leitor/espectador com aspectos de sua percepção fora do comum, mas acessível pelo uso criativo da língua. Em uma oficina de criação de textos teatrais, esses pressupostos permitem trabalhar "de fora para dentro", ou seja, brincar com os traços formais da língua para criar uma figura teatral eficaz. Possibilidades para provocar isso são exercícios que focalizam um conflito enquanto confronto de modos de fala; que fazem seres ficcionais humanas e objetos se comunicar; que estimulam que um ser ficcional entra na fala como em um 
labirinto no qual um elemento temático leva a outro, junto com os respectivos modos de falar; um labirinto do qual surgem eventualmente outras figuras que interagem com ele; ou exercícios que exploram as possibilidades do monólogo "dialógico" enquanto justaposição de modos de falar, e desse modo, justaposição de elementos temáticos.

A possível qualificação desses procedimentos como "pós-dramáticos" quer focalizar o fato que neles o formato do "dramático" não deixa de existir, mas é aproveitado e retrabalhado dentro de explorações poéticas que solapam o drama enquanto fundamento da estrutura da escrita. Mas o que não continua presente é a noção do teatro enquanto confronto, conflito, exploração de um agon. Entretanto, este agon deixa de ser puramente ficcional, e se estabelece como conflito e dúvida na percepção do espectador; uma tensão entre palco e plateia.

No momento em que se encontra minha pesquisa sobre dramaturgia contemporânea, acredito que é mais importante sensibilizar o participante dos princípios estéticos atrás das diversas textualidades contemporâneas, do que inventar exercícios concretos (que por si só nunca garantem resultados ricos e cativantes). Além de explorar as possibilidades da língua na criação de uma escrita teatral, é fundamental fomentar a imaginação formal dos participantes através da leitura de textos contemporâneos. Infelizmente, uma boa parte deles existe somente em língua estrangeira.

\section{Considerações finais}

Os referidos traços formais e seus procedimentos dramatúrgicos têm a tendência de dissolver a construção de uma intriga em diversas (micro)-situações cuja ligação se dá mais por causa de motivos temáticos e discursivos do que de uma intriga causal. Eles igualmente possuem a tendência de dissolver a antiga 'personagem' em uma instância de enunciação sem centro psicológico ou social. O que estrutura essas peças é a relação temática entre subjetividades, contextos culturais ou naturais e história, mediada e expressa pela língua. Os traços pós-dramáticos da dramaturgia contemporânea diferem de traços não-dramáticos antigos - como a linguagem simbólica e alegórica dos Autos por introduzir uma estética predominantemente não-figurativa, cujos elementos verbais tendem à abstração. Isso certamente implica o perigo de criar textos vazios, quando os 
autores não conseguem fazer palpáveis os conflitos e as angustias da subjetividade contemporânea dentro dessa forma. Mas isso talvez não seja culpa da forte presença de traços formalistas, mas de seu uso raso por parte dos autores que esqueceram que a forma não é um fim em si mesmo, mas um meio para elucidar aspectos da realidade vivida pelos espectadores que normalmente passam despercebidos. Ao distorcer a subjetividade empírica, a forma da nova dramaturgia contemporânea pretende desestabilizar o olhar comum dos espectadores sobre si mesmo e apresentar uns insights desconcertantes, mas necessários, sobre a situação histórica do ser humano.

${ }^{1}$ Possui mestrado em Letras Inglês pela Universitat Munchen (Ludwig-Maximilians) (1995), doutorado em Literaturas da língua inglesa pela Universidade Federal de Santa Catarina (2005), e pós-doutorado na ECA/USP (2009-2010) com estudos sobre a dramaturgia brasileira contemporânea. Atualmente é professor efetivo da Universidade do Estado de Santa Catarina na área de história do teatro e dramaturgia. Tem experiência na área de Letras, com ênfase em Dramaturgia e Literaturas Estrangeiras Modernas, e na área de Artes Cênicas, com ênfase em Análise de Montagem, História do Teatro (Teatro Elisabetano, o drama burguês, o teatro pós-dramático), e Estética Teatral. Atua principalmente nos seguintes campos: estudos shakespearianos, teoria da recepção, performance analysis, dramaturgia contemporânea, teatro pós-dramático. Pesquisador CNPq, edital Jovem Pesquisador no. 6/2008. Pesquisador CNPq, edital Jovem Pesquisador no. 6/2008.

${ }^{2}$ Ver, entre outros, os textos de Luis Alberto de Abreu.

${ }^{3}$ Penso, entre outros, em textos de solos teatrais escritos por Fernando Bonassi e as peças surrealistas de Dionísio Neto.

${ }^{4}$ Essa dimensão é relativamente ausente na dramaturgia brasileira contemporânea, mas percebemos uma crescente utilização de procedimentos poéticos, provenientes do campo lírico, como, por exemplo, em trabalhos de Luis Alberto de Abreu ou de Michel Melamed.

5 "O que aconteceu foi [...] o desenvolvimento complicado e sinuoso de novas visões de logotipos múltiplos e um novo tipo de arquitetura. [...] [A] busca e construção de espaços e discursos liberados na medida do possível das restrições de metas (telos), hierarquia e lógica causal.

${ }^{6}$ Traço-estrutura de tudo, sempre habitada pelo traço de algo que não é por si só, as perguntas presençaestrutura.

${ }^{7}$ Como, por exemplo, Shakespeare, ou no século XX, em parte Anton Tchekhov ou Jean Genet, e certamente Samuel Beckett e Heiner Müller.

${ }^{8}$ Ver Baumgärtel, 2010a e 2010b.

${ }^{9}$ Um dos textos fundadores dessa estética é Kaspar de Peter Handke, mas principalmente as peças tardias de Samuel Beckett. Poderíamos citar também como exemplos um pouco mais recentes os textos de Bernard-Marie Koltés, de Michel Vinaver ou de Martin Crimp. Estes últimos não rejeitam a camada representacional e ficcional, mas o centro de significação é claramente o jogo linguístico que os textos estabelecem, entrelaçando o aqui e agora da apresentação com o então e lá do mundo ficcional.

${ }^{10} \mathrm{Um}$ dos grandes modelos dessa intertextualidade é certamente o texto Hamletmáquina de Heiner Müller.

11 discurso, ao contrário dramática ou a linguagem normal de conversação, distingue-se por palavras codificadas, 'buzz frases, muitas vezes com uma dependência de termos técnicos ou jargão. Sublinhando a estratégia de um discurso é uma ideologia essencial e historicidade. Nesta medida, o discurso é o tempo limite. [...] O discurso dá uma frente de caráter ideológico ou fachada que pode ser ativado de forma estratégica para capacitar, intimidar, moralizar, ou para ajudar e informar. Em nova dramaturgia, no entanto, o discurso tende a ser mais do que ruminative argumentativa, mais marginalizados do que mainstream. Ela se move ao longo de Thain, em vez de associação e de repetições incremental por trilhas progressiva da lógica. Neste sentido, é mais dialógica, de dialética. [...] Seu dialógica e dobrados ruminative tende para personalizar o processamento da linguagem.

${ }^{12}$ Matteo Bonfitto (2002) chamou os resultados dessas diferentes estratégias de escrita de "actantemâscara", "actante-texto" e "actante-estado". 


\section{REFERÊNCIAS}

AlveS DE LIMA, Mariângela. "O caos é muito grande", In: ensaio/teatro 5, RJ: edições achiamé, 1981, p. 7-12.

BAUMGÄRTEL, Stephan. “Conflitos estruturais no texto pós-dramático: reflexões sobre o deslocamento do conflito dramático na teatralidade performativa e sua aplicação na dramaturgia brasileira." In: Cássia Navas; Marta Isaacsson; Sílvia Fernandes. (Org.). Ensaios em cena. Salvador, São Paulo, Brasília: 2010a, p. $34-45$.

."Em busca de uma teatralidade performativa além da representação dramática: reflexões sobre a variedade formal na dramaturgia contemporânea." In: Edélcio Mostaço; Isabel Orofino; Stephan Baumgärtel e Vera Collaço. (Org.). Sobre PerformAtividade. Florianópolis: Letras Contemporâneas, 2009, v. , p. 127-179.

. "O sujeito da língua sujeito à língua: reflexões sobre a dramaturgia performativa contemporânea." Revista VIS (UnB), v. 9, 2010b, p. 107-124.

BonfitTo, Matteo. O ator compositor. SP: Perspectiva, 2002.

Castagno, Paul. New Playwriting Strategies. A Language-Based Approach to Playwriting. London\& New York: Routedge, 2001.

FuCHS, Elinor. “The Revenge of writing." Performing Arts Journal, Vol. 9, No. 2/3, 10th Anniversary Issue: The American Theatre Condition, 1985, pp. 163-173.

Lehmann, Hans-Thies, "From Logos to Landscape", In: Performance Research 2 (1), London: Routledge, 1997, p. 55-60. 